\title{
Midwifery students' development of professional competences: A Nordic educational collaboration
}

\author{
Anne-Lise Thoresen and Helle Tvorup Andersen
}

Short intensive courses, where students have the opportunity to be part of an international learning community, are an alternative to student exchange programmes abroad (that typically last from 5 weeks to 3 months). Short intensive courses can provide new experiences and discoveries outside the students' everyday learning environment. The Nordplus Network Freja for midwifery education provides opportunities for student and teacher exchange. Three educational projects developed by the network form the basic material for this chapter. To enhance the understanding of students' learning and knowledge development, the authors have collected and analysed data from the educational projects developed by the Nordplus Network Freja.

\section{Introduction}

As an essential part of qualification for professional practice as a midwife, students are introduced to the knowledge base and professional ethics of midwifery. During their midwifery education, students learn the meaning of professional responsibility and develop an understanding of the autonomy and responsibility of the profession. To develop professional competences as a midwife, students must possess researchbased knowledge, develop clinical skills, and be able to ethically evaluate complex situations. To promote student learning and knowledge 
development, there is a need to develop robust teaching models and strategies that include all aspects of learning in the students' development to professional midwives.

In 2008, 2010, and 2012, three teaching and research projects were planned, implemented, and evaluated by the lecturers of the Nordplus Network Freja, which is a collaborative network between midwife programmes in four Nordic countries. In each project, participants worked on a current topic in midwifery: the prevention, management, and care of perineal trauma. The projects were carried out as three individual projects but were based on the same teaching methodology and model (Figure 1).

In this chapter, the authors focus on the qualitative data from the three projects. The specific context of the projects and arguments for the choice of the midwifery topic and teaching methodology are described later in the chapter and shed light on how the projects were implemented and how the data were developed. The data consist of reflection logs, travelogues, and consensus reports that have been transcribed in one common document. The data were analysed using a qualitative analysis model revealing knowledge of students' individual experiences, in addition to shared experiences and knowledge developed through dialogue and collaboration by all participants. The goal of analysing and interpreting the data is to generate new insights into aspects of learning that can promote the development of midwifery students' professional competencies.

\section{Background}

The International Confederation of Midwives (ICM, 2013) emphasises that professional competence can be developed through various formal processes based on the ICM (2013) standard for midwifery education. Midwifery education must have a well-defined philosophy and demonstrate clear values that provide direction for the students' professional development. The ICM (2013) further states that lecturers involved in midwifery education should encourage the continuous development of the education programme and maintain its integrity through a consistent, equitable, and clear educational process. The ICM (2013) also underlines the importance of introducing students to a learning philosophy based on the principles of lifelong learning. Midwifery education should provide students with 
insight into the autonomy of the midwife and the qualifications needed by a professional midwife.

According to Judith T. Fullerton, Joyce B. Thompson \& Peter Johnson (2013), professional competences can be viewed from three perspectives. In the first perspective, necessary basic knowledge and understanding must be integrated into midwifery practice and evident in the midwife's actions. The second perspective is the midwife's ability to think critically and is defined as a capacity that can enhance professional practice. A third perspective is a holistic approach which includes, in addition to the first two perspectives, the importance of understanding the context of midwifery actions, where ethics and values are included in the competent practice of the profession.

Sigridur Haldórsdóttir \& Sigfridur Inga Karlsdóttir (2011) have developed an evolving theory of professionalism in midwifery, where they suggest that curriculum planning should always involve theories and models regarding professionalism in midwifery and always include professional caring and wisdom, interpersonal competence, and personal and professional development. The development of professional competence must be evident in the development of curricula, which must emphasise the evaluation of student midwives' attitudes, interpersonal competence, and self-care, rather than only their cognitive and practical competences. This statement is underpinned in Lynn Nicholls \& Christine Webb's (2006) review, in which they conclude that a good midwife must be more than just technically skilled in providing physical care and they affirm the importance of communication as a key aspect of midwifery skills. Communication has implications for how a midwife interacts with women and their families, integrates research- and experience-based knowledge, and for how she understands the midwifery profession.

Sara E. Borelli (2013) highlights that midwifery education lays the foundation for the development of students' professional competencies as midwives, which requires attributes such as theoretical knowledge, professional skills, personal qualities, communication skills, and moral/ethical values. Michelle Butler, Diane Fraser, \& Roger Murphy (2008) identified essential midwifery competencies at the point of registration: being a safe practitioner, having the right attitude, and being an effective communicator. To enable students to develop into reflective and autonomous midwives, reflection must be included in the learning and teaching strategies throughout their education. Reflective learning processes, according to Janice Bass, Jennifer 
Fenwick, \& Mary Sidebotham (2017) and Kathleen Nakielski (2005), will allow students to develop their awareness and critical reflection. Linda Sweet, Janice Bass, Mary Sidebotham, Jennifer Fenwick \& Kristen Graham (2018) and Mieke Embo \& Martin Valcke (2017) highlight the importance of enabling midwifery students to develop an awareness of continuous professional development and of becoming lifelong learners.

The following research question was drawn up to gain insight into the students' experiences:

How can midwifery students develop professional competencies through participation in Nordic learning projects?

\section{A Nordic learning context}

The Nordplus Network Freja was established in 2004 and consisted of the four midwifery programmes at UiT The Arctic University of Norway in Tromsø, University College of Northern Denmark in Aalborg, Umeå University in Sweden, and Novia University of Applied Sciences in Vaasa, Finland. In addition to student and teacher exchanges, the collaboration between the four programmes led to the development, implementation, and evaluation of three teaching and research projects in 2008, 2010, and 2012. The projects initiated by the teachers in the network received funding from the Nordic Council of Ministers, and each project was worth 3 European Credit Transfer and Accumulation System (ECTS) points. A total of 36 students, 12 clinical supervisors, and eight midwifery teachers participated in the three projects. In each project, there were 12 students, four teachers and four clinical supervisors from the four midwifery programmes. All participants were females who spoke a Nordic language.

The midwifery education provided by the Universities in the Nordplus Network Freja is regulated both by national educational policies and by European Directive 2013/55/EU (European Parliament, 2013), which addresses the content of midwifery education and quality requirements for accreditation. However, the midwifery education programmes in the four participant countries vary in degree, length, structure, and content. One common feature is that learning takes place in both the educational institution 
and in clinical practice, where theory and practice are integrated to support student learning.

In each project, participants worked on a current topic in midwifery: the prevention, management, and care of perineal trauma. The prevailing statistics for birth-related ruptures and trauma differ in the four countries (Laine, Rotvold \& Staff, 2012), and was an important reason for launching three projects. This topic was selected both to generate interest in midwifery research and to foster evidence-based midwifery practice. This comprehensive approach provided students with an opportunity to develop their professional knowledge of perineal trauma and its influence on and implications for the physical, reproductive, and psychosexual health of women and girls (Kettle \& Reynor, 2010; Aasheim, Vika Nilsen, Lukasse \& Reinar, 2011). The exploration of the prevention, management and care of perineal trauma led to the consideration of several professional midwifery perspectives, including values and belief systems, cultural and ethnic origins, and personal and professional desires and goals, all of which are important aspects in students' development of professional competencies.

The initial aim was to give midwifery students the ability to enhance their theoretical, practical, and ethical knowledge of the topic of prevention, management, and care of perineal trauma. A secondary aim was to share knowledge, traditions, culture, and other aspects of midwifery theory and practice in each of the four countries.

The educational projects established a new learning environment, where online group learning prepared the participants for an intensive week of faceto-face teaching and learning (Figure 1). Participants were divided into three groups of six members each: one midwifery student from each of the four countries, one of the lecturers, and one of the clinical supervisors. The groups were introduced to each other in three online meetings, and later met physically for the 5-day face-to-face intensive course. During the group work, the students primarily supervised one another as peers with a teacher and a clinical supervisor present. The arrangement and composition of the groups included peer learning, as described by Topping (2005). Participants' presentations of their group work on the last day of the intensive week were an important element of the course, aiming at how the group had developed an evidence-based understanding of preventing perineal trauma. The lecturers led the discussions and collected material to create a consensus report. 


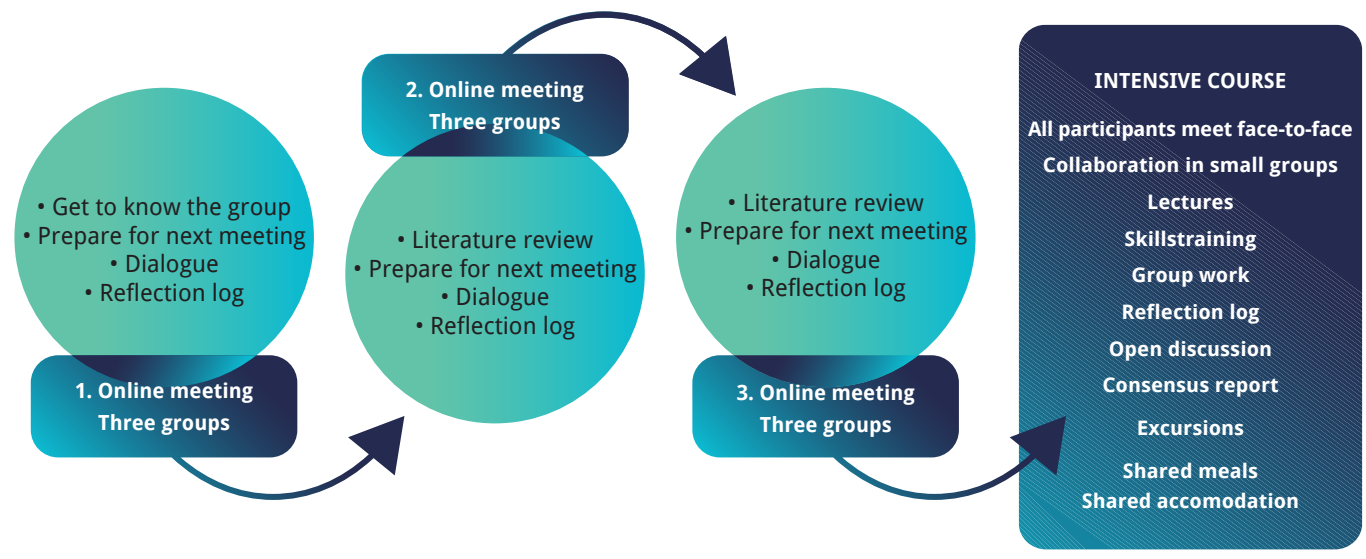

Figure 1: The teaching and action model

\section{Theoretical perspectives}

\section{Sociocultural learning theory}

Planning the first project included a focus on developing a robust teaching and research design that could be applied to several subsequent projects. Michael Cole (1996) argues that the practice of teaching can be considered as one of the most important and most complex mediating systems of our culture. The preparation of teaching for midwifery students from four Nordic countries involved a combination of insight into each country's midwifery education, development of mediating tools and actions, and integration of historical and contextual knowledge. James Wertsch (1998) states that there is a mutual influence between people's mental activity (the mind) and the context they act in (the world). In the development of the projects, it was emphasised that the teaching methods needed to include various elements of interaction, using mediating tools such as written and oral dialogues. Luis Moll (2001 p. 113) emphasises that thinking is developed in collaboration with others, where mediating tools using both written and oral language play a pivotal role in the formation and development of our intellectual abilities. To ensure a solid theoretical foundation, the three projects were grounded in sociocultural learning theory and action research.

A sociocultural learning perspective emphasises that all human actions are the result of social, cultural, and historical experiences mentally processed 
by the individual, and that knowledge is developed through participation and interaction between people (Dysthe, 2000).

Jean Lave \& Etienne Wenger's (1991) understanding of the sociocultural learning perspective proposes that learning is a fundamentally social phenomenon that occurs in communities of practice. Learning takes place through participation: the participants contribute different knowledge and skills. To enable participants to gain insight into various theoretical, practical, and ethical elements of the topic, it was important to create learning activities that included students, midwives, and teachers. An important perspective in the development of these activities was to ensure that all participants had equal but complementary roles, and that they constituted a resource for learning and knowledge development. In this understanding, learning is situated in a specific social and cultural situation. Wenger's (1998) social theory of learning emphasises the importance of placing learning in the context of the experiences we gain through participation in communities of practice where work - learning and development are not separate but integrated. Participation in a community of practice involves gaining experience of the community's language, rules, and concepts and understanding how these are used.

\section{Action research processes}

According to Jean McNiff (2014), action research is about people thinking, working, and creating knowledge together, making a commitment to improvement and putting ethics into practice. In the projects, students, midwives, and teachers were obliged to collaborate by way of dialogical processes. Importantly, the participants needed to feel involved in the interaction with the other participants, who all contributed to developing and deepening midwifery knowledge on the topic of prevention, management, and care of perineal trauma. The learning process included collaboration, critical reflection, and dialogue through continuous and circular reflective processes, where midwifery knowledge was critically assessed with a view to enhancing professional practice in encounters with women who receive midwifery care. In addition to their roles as teachers and coordinators, the teachers' role as researchers involved developing data to document the research processes. Karin Rönnermann and Anette Olin (2014) refer to such processes as research circles, involving systematic and well-organised collaboration 
between participants who conduct research and other participants, with a clear distribution of work between the participants. In the different phases in the research process, the students and teachers revised the literatures and skills training collaboratively and decided the need to change different themes for increased student learning. The teachers developed a structured teaching plan, using an action research approach to ensure and understand both learning and research aspects of the projects.

\section{Developing the data}

In this study, the students writing reflection logs as a structured learning method is an example of a mediated learning activity that is both individual and social. When writing, the learner is in a continuous dialogue that extends forwards and backwards in time. Mikhail Bakhtin's (1996) theory of dialogue posits that meaning and understanding are not transmitted from one person to another but emerge in the communication situation itself, in which different voices confront one another and expand mutual understanding. A dialogue can enable one to consider the perspectives of others and to relate them to one's own. New insights and opinions will emerge in the dialogue, at both an individual and social level.

Students reflection on their own learning was a structured, integral part of all learning activities. Questions such as 'What did you do yourself?', 'What did you do as a group?', 'How can you use what you have learned?' were used to enhance students' awareness of their own learning. The written individual reflection logs were a daily learning activity and formed a basis for dialogue in small and large groups. The lecturers could integrate this knowledge into subsequent learning activities and dialogue with the participants. In this way, the knowledge was put to the test and led to development and critical reflection, enabling the participants to share knowledge.

Following each project, evaluation forms and reflection logs were summarised, transcribed, and discussed by the lecturers to provide insight into the students' learning experiences. This enabled the specific teaching and learning activity of each project to be raised to a meta-level through dialogue and reflection. In this learning and research process, which included the teachers, the experience and knowledge gained collectively by all participants were 
integrated with research-based pedagogical knowledge to provide a deeper understanding of the learning processes involved.

To develop data that could document the students' experience and learning, the teachers, here researchers, chose to use reflection logs consistently throughout the programme. The reflection logs represented the students' reality as their opinions and perceptions of their learning and knowledge development. Through the research underpinning this chapter, students' written experiences are included as part of the content of the chapter. Paul Ricoeur's (1977) principles for the development of significant data are thus considered in the research processes discussed here.

The data were derived from a variety of sources: 1) students' reflective journals describing their learning processes during the online sessions and the intensive weeks; 2) three written consensus reports based on dialogue and interaction; 3) three group diaries; and 4) evaluation data that included questions about personal preparation, academic preparation, and learning outcomes. The questionnaires included both alternative responses to be ticked and fields to enter text. Handwritten reflection logs from 36 students were transcribed into Microsoft Word documents, totalling about 60 A4 pages, while the three consensus reports amounted to three A4 pages. The free text part of the questionnaires was transcribed to about $30 \mathrm{~A} 4$ pages. The total qualitative data from the three projects thus consisted of 93 A4 pages. The three consensus reports were developed in collaboration and dialogue between the participants. The reports described the knowledge of the prevention, management, and care of perineal trauma that the participants had developed during each course. This kind of dialogic process, where knowledge is summarised and anchored in mutual understanding of a topic, can be described as member checking (Lincoln, Guba \& Pilotta, 1985), which enhances the credibility of a study.

\section{Ethical implications}

The data contained no personal information that could be traced back to individual participants. In each of the three projects, participants were given written information about the aims, content, and structure of the project. They were told that the reflection logs and evaluation forms would constitute the data to be analysed. All participants provided written informed 
consent, and all were given information about anonymization of the data. No data developed during the three projects were associated with participant names. The quotes used in this chapter have been translated from Swedish, Norwegian, and Danish into English, and are presented as examples and illustrations of the participants' experiences.

\section{Analysis}

A thematic analysis (Lindseth \& Norberg, 2003) was used (Figure 2). The authors of this chapter individually and collectively read the material systematically to find a deeper meaning and developed themes relevant to the research question. To validate the analysis, two external researchers not involved in the projects assisted in the process and consensus was reached on the themes that emerged as the results of the studies. For a deeper insight into the analysis process, please refer to Thoresen \& Norbye (2019).

\section{Naive reading}

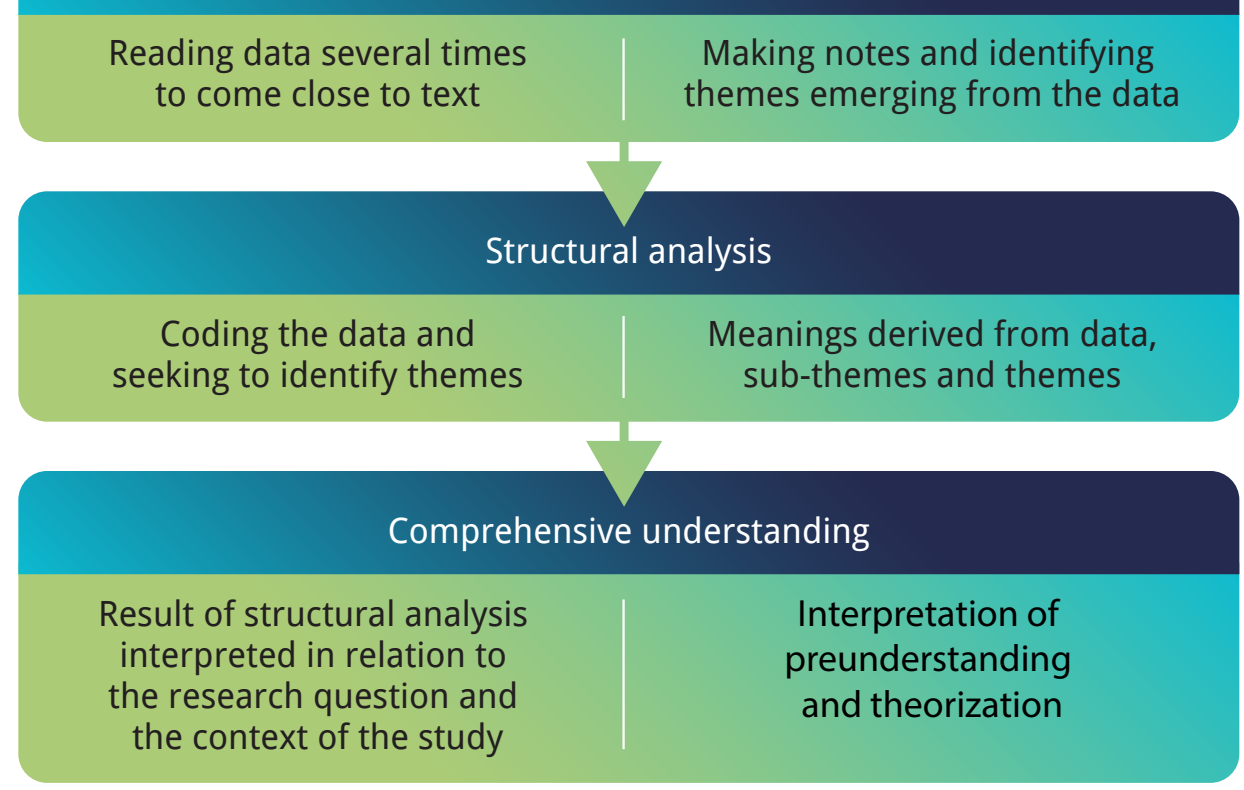

Figure 2. The analysis processes 


\section{Results}

The study described in this chapter is based on the analysis of data from three teaching and research projects conducted by the Nordplus Network Freja. Analysis of the research question 'How can midwifery students develop professional competence through participation in Nordic learning projects?' has resulted in three themes: 1) Students gained experience of midwifery knowledge development and 2) developed insights into woman-centred care; and 3) the students felt that they were part of a midwifery community. In the presentation of the results, participants' quotes are given in italics.

\section{Experience of midwifery knowledge development}

The data analysis reveals that the students gained insight into knowledge development in an important midwifery topic, developing an awareness of their own learning, experience, professional development, and personal growth. Dialogue, reflection, and collaboration in large and small groups enabled students to gain experience of knowledge development and learn the importance of sharing knowledge, and thus became aware of the diversity of learning aspects involved in the topic of prevention and treatment of perinatal lacerations.

Our discussions on the topic have strengthened and increased my theoretical knowledge, my personal experiences, my attitudes, and my ability to see an issue from different points of view. I now have more of a focus on risk factors, evidence, hand skills and birth positions. (Midwife student 2012)

The importance of sharing evidence-based knowledge. The importance of reading and discussing scientific papers. The strategies and skills to prevent perineal trauma during childbirth. (Midwife student 2010) 


\section{Midwifery philosophy and woman-centred care}

The students came to realise the importance of the midwife's responsibility to work in a woman-centred manner, and the importance of communicating with the woman to gain insight into her life and to help her understand how her experiences might affect the development of her pregnancy, the birth outcome, and her attachment to the baby. Students gained experience in discussing complex ethical issues that emerged through the learning process.

The importance of appropriate communication between the woman and the midwife concerning the perspectives of the woman. Focus on ethical challenges, the women's autonomy and their personal experience. (Midwife student 2012)

Perineal trauma can cause lifelong suffering for women. Important to prevent perineal trauma. Important to give the right treatment. Important to give postpartum care. (Midwife student 2010)

Many women suffer in silence and don't seek help for their problems. Especially in countries where women are poor. Communication with the woman to gain insight into her situation. (Midwife student 2010)

\section{The feeling of being part of a midwifery community}

The Nordic learning context helped the students to experience the importance of being part of a midwifery community. The students described this learning community as a setting where they developed solidarity, bonds, and belonging, and where they took part in each other's thoughts and work. The students experienced security and respect by being able to display both strong and weak aspects of themselves and their knowledge. Guidance by the lecturers and the clinical supervisors enhanced the students' learning and insight into how the midwife community develops knowledge and competence.

The social activities, which included excursions and shared meals and accommodation, seemed to make a positive contribution to this community. 
The students expressed their experience of a midwifery community in different ways.

It was very good to share experiences with other students. We've developed a sense of solidarity. (Midwife student 2010)

I've learned a lot about the other participants and that there are differences between the midwife's tasks in the Scandinavian countries. I have begun to get new perspectives on midwifery. You can do things in different ways than I've experienced in my practice. (Midwife student 2008)

Then there were all the social aspects: a nice feeling of community with the other participants from all over Scandinavia, both in the group work and socialising in the evenings. This was an enriching experience in many ways. In particular, exchanging experiences with students from the other Nordic countries gave us a good insight into how they approach midwifery there. (Travelogue 2012)

\section{Discussion}

In this chapter, we have asked the following research question: How can midwifery students develop professional competence through participation in Nordic learning projects? We have described how the data were developed and analysed in connection with the learning context the prevention, management, and care of perineal trauma. This topic requires advanced midwifery knowledge and skills and demonstrates the midwife's moral responsibility to care for women giving birth. When working on this topic, students shared knowledge, traditions, and different aspects of midwifery theory and practice from each of the four countries. 


\section{Learning strategies to promote professional competence in midwifery education}

Fullerton et al. (2013) discuss the concept of competency-based education (CBE) in relation to the education of midwives and how this approach can help to develop the professional role of the midwife in society. The modern midwife role emphasises the development of evidence-based knowledge and the principles of lifelong learning. Knowledge is in constant flux, and the midwife needs a clear focus on collaboration with the pregnant woman and her partner. CBE highlights the importance of well-thought-out and robust learning strategies that can support and engage students in their professional development (Fullerton, 2013). All higher education must include evidence-based knowledge, a focus on student activity and students' responsibility for their own learning.

Fullerton et al. (2013) emphasise that students must be allowed to develop their ability to reflect and think critically to enable them to gain insight into their own learning process and to develop ways to understand what they have learned and the consequences of this for practice. The midwifery students emphasised reflection as important for insight into their learning and knowledge development. Nakielski (2005) suggested reflection logs as a tool for reflective practice in midwifery and emphasised writing as a structured learning activity. When students write reflective logs, they can develop both professional and personal knowledge. Writing in this context can link theory to practice and promote problem-solving skills, self-awareness, and critical thinking. Writing reflection logs can help prepare students for lifelong learning and continued reflective practice (Collington \& Hunt, 2009; Nakielski, 2005).

The holistic reflection model by Bass et al. (2017) highlights the importance of structured reflection to develop critical reflection and reflective practice in midwifery education. The model consists of six phases: 1) self-awareness, 2) description, 3) reflection, 4) knowing, 5) evaluation (analysis), and 6) learning (synthesis). The six phases provide theoretical insight into how student reflection can lead to the development of knowledge in which they can synthesise, integrate, and identify what they have learned, and integrate others' knowledge in their own development. What is important is that students discover how to understand and transform this knowledge and integrate it into their midwifery practices (Bass et al., 2017). Sweet et al. (2018) found that this model helped students to adopt a holistic approach to reflection by 
integrating existing knowledge with new insights and understanding within the framework of a holistic midwifery philosophy. The studies by Bass et al. (2017) and Sweet et al. (2018) highlight several similarities to experiences from the study described in this chapter. By integrating reflection as a written, dialogue-based, learning activity, the midwifery students appeared to develop self-insight through the opportunity to describe what they had learned, to discover the meaning of reflection as an integral part of learning and knowledge development, and to discuss and understand how the knowledge could be used in midwifery practice.

Embo \& Valcke (2017) emphasise the importance of systematic reflection processes as a method to understand the midwife's responsibility to engage in lifelong learning. Bass et al. (2017) highlighted reflexive conversations as a tool for developing awareness and professional engagement. The students in our study emphasised the importance of dialogue and cooperating in groups in which they helped each other to learn (Topping, 2005), but also considered dialogue with the clinical midwives and teachers as an important learning resource. The open discussions among all participants were led by the teachers and clinical midwives, providing students with experience in identifying and integrating theory and practice.

Midwifery philosophy, evidence-based knowledge, integration of theory and practice, and the development of ethical and personal knowledge are all important elements for the development of professional competences as a midwife, according to Fullerton et al. (2013). Reflection processes that include a description of what students have learned and how to use this can help students shift their understanding towards a more transformative form of learning where they synthesise their knowledge, as emphasised by Bass et al. (2017).

The students demonstrated insight into how theory and practice are integrated into midwifery and developed a holistic perspective where the individual childbearing woman is placed at the centre of midwifery practice. An important perspective of professional development for midwives is precisely the ability to integrate all available knowledge into action, as described by Fullerton (2013). Bass et al. (2017) and Nakielski (2005) emphasise the importance of students' ability to clearly identify links between theory and practice through dialogical reflection, and later to connect theory to practice as they develop into reflective practitioners. Bass et al. (2017) also highlight dialogue as an important reflection tool that cultivates awareness of one's 
own learning, fosters engagement, and helps students to adjust their views, insights, and practices. In our study, dialogue and interaction in small and large groups formed a significant part of the learning strategy, suggesting that dialogue and collaboration enabled the students to process and become more aware of their own learning. Participating in dialogue and being involved in the knowledge development of the other participants enabled common learning. In this learning community, clinical midwives, teachers, and students jointly identified and developed midwifery knowledge through dialogue and reflection on their practice. Knowledge of the topic on the prevention, management, and care of perineal trauma was clearly described in the consensus reports. Such cooperative learning might be understood in relation to Vygotsky's (1978) concept of the zone of proximal development, demonstrating the importance of cooperation with others as an intensive stage in learning.

Midwives' responsibilities and care for women through pregnancy, childbirth, maternity, and early parenting (WHO, 2019; ICM, 2013) are described as woman-centred care. The term describing a holistic approach to cooperation between the midwife and the woman, where the woman's social, emotional, physical, spiritual, and cultural needs are identified through collaboration and dialogue between the two. Midwives must be capable of promoting health and preventing complications before they occur (Fullerton, 2013). By working on the topic of prevention, management, and care of perineal trauma, the students became aware of the importance of placing the woman and child at the centre of their actions. McMullan et al. (2003) point out that professional competence is expressed in observable actions, and that each action must be based on the relevant necessary knowledge. Also, the context must be included in the understanding of professional competence; here, ethics and values must form part of the action. The students in this study were able to focus on evidence-based knowledge of the topic, insight into different methods for the prevention of perineal lacerations, assessment of injuries, and training in saturation techniques. The contextual aspect that includes cooperation and communication with the woman was highlighted as a significant factor in the development of professional competence, where ethical perspectives were also discussed. Haldórsdóttir \& Karlsdóttir's (2013) theory of the development of professional competence in midwifery underlines that the professional midwife cares for the childbearing woman and her family and this caring within the professional domain is seen as the core of 
midwifery. The students stressed the importance of a woman-centred focus as the essence of midwifery. The midwife must use communication and interaction with the woman to gain insight into her situation and must act ethically and responsibly. Borelli (2013) points out that the midwife's professional actions in the encounter with the individual woman should integrate theoretical knowledge, clinical and professional competencies, communication skills, personal qualities, and moral and ethical attitudes.

\section{Implications for teaching and learning practice}

The students in this study gained experience of developing knowledge in a midwifery community in which they were active participants in their own and others' learning process. Developing professional competence as a midwife will mean that students discover a knowledge base for good midwifery practice. Through experience sharing, dialogue, and interaction, the students learned to view their own self-understanding in relation to societal demands for good midwifery practice. Bakhtin's (1981) theory of dialogue helps us to understand how multiple voices exist simultaneously. The different voices may be opposed to one another, they may challenge or complement one another, or they may be in a dialectical relationship to one another in other ways. In this study, the dialogue included an exchange of experiences regarding the theoretical, practical, and personal ethical knowledge involved in midwifery. Critical reflection in this context is related to understanding the main topic based on the professional perspectives of several midwives. In this learning context, the participants developed knowledge and planned how this knowledge could be presented to the other participants in the course.

A sociocultural learning perspective emphasises that all human actions are the result of social, cultural, and historical experiences that are mentally processed by the individual (Dysthe, 2001). In this study, the students experienced being part of a midwifery community. They reported gaining insight into each other's education, experiencing minor linguistic challenges, and learning how the supervision of practice took place in different ways. The students described an experience of solidarity, belonging, and friendship. Lave and Wenger's (1991) theory of situated learning describes learning and identity development in workplace learning, arguing that it is too narrow to regard knowledge as something individual. Knowledge is developed through 
legitimate peripheral participation. In this learning context, cooperation involved students, midwifery teachers, and clinical supervisors. The student's position was that of a newcomer, whereas the lecturer and clinical supervisor were more competent and experienced. The positions were complementary, and the participants had different roles. Students were introduced to the entire midwifery profession through culture, language, and identity. Midwifery knowledge and culture are understood as integrated knowledge, which was developed through social interaction and various forms of cooperation within the groups.

We see that the pedagogy used in this study contributed to the development and awareness of theoretical and practical knowledge, professional skills, personal qualities, communication skills and ethical values, which are all important attributes for the development of professional competence as a midwife. Haldórsdóttir \& Karlsdóttir (2011) created a theoretical framework to understand the development of midwifery competence, highlighting the preparation of midwifery students to work within a discipline that is both scientific and practical. They emphasised professional caring and wisdom, interpersonal competence, and personal and professional development as significant qualifications that must be developed by the student. Butler, Fraser, $\&$ Murphy (2008) refer to the importance of including personal attributes and communication as important professional skills. Being involved in midwifery education and research is an important requirement and working with and caring for women as individuals are essential competencies (Nicolls \& Webb, 2006).

\section{The Nordic context}

The participants were introduced to learning strategies that involved dialogue, critical reflection, and cooperation in this learning community. Professional learning communities include participants from different levels and backgrounds, as seen in the Nordic context of this study. By participating in dialogue, oral and written reflective activities, and cooperation, students move from peripheral to active engagement in the learning and knowledge community. Rasmussen \& Grønmo (2013) highlighted the importance of students learning cooperation between courses of study, close links between research 
and education, and short-term student exchanges. Mixing students across Nordic borders in short-term exchanges seems to provide an obvious platform for students to gain skills in practical midwifery and to learn how practices differ between the Nordic countries. The participants revealed that the opportunity to meet foreign students in learning communities entailed a positive approach to one another and the enhancement of midwifery knowledge.

\section{Conclusion}

This study demonstrates how an action research approach, systematic learning, and reflection activities can enhance midwifery students' learning and development of professional competence. Recent research on midwifery students' development of professional competence has provided new insights into the projects developed and implemented in the Nordplus Network Freja. Three central themes emerged as important for the development of professional midwifery competence: knowledge development, the focus on providing woman-centred care, and the participants' experience of a midwifery community.

The Nordic learning community was created in which the participating students experience knowledge development in a Nordic collaborative learning context. Students were allowed to get to know and discover themselves as professionals in a context involving different dialogical and cultural challenges from their everyday experience, promoting critical reflection and reflective practice, thereby linking theory and practice.

\section{Implications for practice}

The development of professional competence is important for health professional education. By developing learning communities based on sociocultural learning theory, action research, and systematic learning strategies that contain clear elements of reflection, dialogue, and collaboration, one may present students with a holistic professional understanding. 
The experiences described in this chapter may be an inspiration for the development of short-term international exchanges in midwifery and other professional education. Short-term international exchanges of this type could be important for students who are unable to spend a long period abroad.

\section{Limitations}

The action research approach provided us with the opportunity to develop the data during the three projects. The fact that we, the authors, participated in the projects might have influenced the analysis and results.

\section{Acknowledgement}

A special thank you to all the midwifery students, clinical midwives, and teachers who participated in the projects.

\section{References}

Aasheim, V., Vika Nilsen, A. B., Lukasse, M., \& Reinar, L. M. (2011). Perineal techniques during the second stage of labour for reducing perineal trauma. The Cochrane Database Systematic Review, 12, CD006672.

DOI: https://doi.org/10.1002/14651858.CD006672.pub3

Bakhtin, M. M. (1981). The dialogic imagination: Four essays by M. M. Bakhtin. Austin, TX: University of Texas Press.

Bakhtin, M. M. (1996). The problem of speech genres. In C. Emerson \& M. Holmquist (Eds.), Speech genres and other late essays. p. 60-102. Austin, TX: University of Texas Press.

Bass, J., Fenwick, J., \& Sidebotham, M. (2017). Development of a model of holistic reflection to facilitate transformative learning in student midwives. Women and Birth: Journal of the Australian College of Midwives, 30 (3), p. 227-235.

DOI: https://doi.org/10.1016/j.wombi.2017.02.010 
Borelli, S.E., (2014) What is a good midwife? Insights from the literature.

Midwifery, Volume 30, Issue 1, January 2014, p. 3-10

DOI: https://doi.org/10.1016/j.midw.2013.06.019

Butler, M. M., Fraser, D. M., \& Murphy, R. J. L. (2008). What are the essential competencies required of a midwife at the point of registration? Midwifery, 24

(3), p. 260-269. DOI: https://doi.org/10.1016/j.midw.2006.10.010

Cole, M. (1996) Cultural psychology. Cambridge: Harvard University Press

Collington, V., \& Hunt, S. C. (2009). Reflection in midwifery education and practice: An exploratory analysis. Evidence Based Midwifery, 4 (3), p. 76-82. Gale Academic OneFile, https://link.gale.com/apps/doc/A167030957/AONE?u= anon $-\mathrm{fc} 4 \mathrm{c} 9760 \&$ sid=bookmark-AONE\&xid=f1 1f100b. Accessed 2 Nov. 2021.

Dysthe, O. (2001). Sosiokulturelle teoriperspektiv på kunnskap og læring. In O.

Dysthe, (Ed) Dialog, samspel og lering 2001. Oslo: Abstrakt forlag.

Embo M., \& Valcke M. (2017). Continuing midwifery education beyond graduation: Student midwives' awareness of continuous professional development. Nurse Education in Practice, 24, 2017, p. 118-122, ISSN 14715953, DOI: https://doi.org/10.1016/j.nepr.2015.08.013

European Higher Education Area (1999). The Bologna Declaration of 19 June 1999. https://www.eurashe.eu/library/bologna_1999_bologna-declaration-pdf Accessed 2 Nov. 2021.

Halldórsdóttir, S., \& Karlsdóttir, S. I. (2011). The primacy of the good midwife in midwifery services: An evolving theory of professionalism in midwifery. Scandinavian Journal of Caring Sciences, 25 (4), p. 80-6817. DOI: https://doi.org/10.1111/j.1471-6712.2011.00886.x

International Confederation of Midwives (ICM). (2013). Essential competencies for basic midwifery practice. https://internationalmidwives.org/our-work/policy-andpractice/essential-competencies-for-midwifery-practice.html Updated 2019. Retrieved from www.internationalmidwives.org. 03.11.2021

Kettle, C., \& Raynor, M. D. (2010). Perineal management and repair. In J. E. Marshall \& M. D. Raynor (Eds.), Advancing Skills in Midwifery Practice. Churchill Livingstone: Elsevier.

Laine, K., Rotvold, W., \& Staff A, C. (2012). Are obstetric anal sphincter ruptures preventable? - Large and consistent rupture rate variations between the Nordic countries and between delivery units in Norway. Acta Obstetricia et Gynecologica Scandinavica. DOI: https://doi.org/10.1111/aogs.12024 
Lave, J., \& Wenger, E. (1991). Situated learning: Legitimate peripheral participation. New York, NY: Cambridge University Press.

Lincoln, Y. S., Guba, E. G., \& Pilotta, J. J. (1985). Naturalistic Inquiry. Thousand Oaks, CA: Sage Publications.

Lindseth, A., and A. Nordberg. (2004). A Phenomenological Hermeneutical

Method for Researching Lived Experience. Scandinavian Journal of Caring

Sciences, 18 (2): p. 145-153.

DOI: https://doi.org/10.1111/j.1471-6712.2004.00258.x

McMullan, M., Endacott, R., Gray, M. A., Jasper, M., Miller, C. M. L., Scholes, J., $\&$ Webb, C. (2003). Portfolios and assessment of competence: a review of the literature. Journal of Advanced Nursing, 41 (3), p. 283-294.

DOI: https://doi.org/10.1046/j.1365-2648.2003.02528.x

McNiff, J. (2014). Writing and doing action research. London, UK: Sage.

Mead, G. H. (1934/1972). Mind, self and society: From the standpoint of a social behaviorist. Chicago, IL: University of Chicago Press.

Moll, L.C. (2001) Through the Mediation of others: Vygotskian Research on Teaching. In V. Richardson (red.). Fourth Handbook on research om Teaching. Washington DC: American Educational and Research Association.

Nakielski, K. P. (2005). The reflective practitioner. In M. D. Raynor, J. E. Marshall, \& A. Sullivan (Eds.), Decision-Making in Midwifery Practice. New York, NY: Churchill Livingstone.

Nicholls, L., \& Webb, C. (2006). What makes a good midwife? An integrative review of methodologically diverse research. Journal of Advanced Nursing, 56 (4), p. 414-429. DOI: https://doi.org/10.1111/j.1365-2648.2006.04026.x

Rasmussen, A., \& Grønmo, S. (2013). Hva er kvalitetsutdanning? [What is quality education?]. Bergen: Centre for Internationalisation of Education. Retrieved from https://pahoyden.khrono.no/kronikk/hva-er-kvalitetsutdanning/304000 09.11 .2021

Ricoeur, P. (1977). The question of proof in Freud's psychoanalytic writings. Journal of American Psychoanalytic Association 25, p. 835-871.

DOI: https://doi.org/10.1177\%2F000306517702500404

Rönnerman, K. and Olin, A. (2014). Research Circles. In K. Rönnerman and P. Salo (Eds) Lost in Practice: Transforming Nordic Educational Action Research, p. 95112. Rotterdam/ Boston/Taipei: Sense Publishers 
Sweet, L., Bass, J., Sidebotham, M., Fenwick, J., \& Graham, K. (2019). Developing reflective capacities in midwifery students: Enhancing learning through reflective writing. Women and Birth, 32 (2), p.119-126.

DOI: https://doi.org/10.1016/j.wombi.2018.06.004

The European Parliament. (2013). Directive 2013/55/EU. Retrieved from https://eur-lex.europa.eu/LexUriServ/LexUriServ. do?uri=OJ:L:2013:354:0132:0170:en:PDF 09.11.2021

Thoresen, A. L., \& Norbye, B. (2019). Reflective writing followed by dialogue improves supervision practices and cooperation in education. Educational Action Research, 2021, 29 (1) p. 149-164.

DOI: https://doi.org/10.1080/09650792.2019.1679653

Topping, K. J. (2005). Trends in peer learning. Educational Psychology, 25 (6), p. 631-645. DOI: https://doi.org/10.1080/01443410500345172

Wenger, E. (1998). Communities of Practice. Cambridge, UK: Cambridge University Press. 